\title{
BRITISH IRON AND STEEL RESEARCH ASSOCIATION WORK AT SHEFFIELD LABORATORIES
}

\begin{abstract}
$\mathrm{T}$ HE laboratories of the British Iron and Steel Research Association in Sheffield, which have recently been opened, have been built to provide laboratory and plant facilities for three of the Association's five divisions-those concerned with steelmaking, metal-working and metallurgy.

They have been planned in part to overcome a difficulty met with in much industrial research and particularly in that connected with the iron and steel industry. This is the very great difference in scale between laboratory bench-work and industrialplant operations, which tends to make experiment on operating plant extremely expensive and diminishes the value of much preliminary work.

In addition to the more usual research facilities and offices, therefore, there are at Sheffield two so-called 'plant laboratories' in which experiments not far removed from the scale of steelworks operations can be carried out. They contain, in particular, an electric arc furnace, a rolling mill, a forging press and a high-speed wire-drawing machine. The plant laboratories are single-story buildings of $10,000 \mathrm{sq}$. ft. and 4,000 sq. ft. floor area respectively. There is a third new building, a three-story main block of approximately 30,000 sq. ft. floor area. There are also four buildings which were previously on the site, one of which is occupied by the Cutlery Research Council, an independent body which makes use of the Association's central administrative services, and works in close liaison with the three divisions of the Association.
\end{abstract}

\section{Steelmaking Division}

The Steelmaking Division is naturally concerned particularly with fuel efficiency, and carries out many field-trials and observations on industrial furnaces. Fairly recent extensions concern the measurement of flame heating-power and its relationship to changes in furnace-operating conditions. This is an attempt to apply in steelworks practice the results of the work of the International Flame Radiation Committee on the experimental furnace at Ijmuiden.

One of the Ijmuiden results requiring further study is that steam reduces flame-radiating power, yet an increase in steam/oil ratio is known to give faster melting in many furnaces. This may be due to severel combined effects; for example, increase of steam will increase the momentum of the jet, and may therefore increase the convective heat transfer, which is known to be very important during the melting-down stage.

Other field-work related to fuel efficiency is that concerned with the infiltration of cold air in open. hearth furnaces. Two techniques of measuring the air or gas flow in the flue system of such furnaces have been developed. The first was based on Pitot tube surveys across sections of the system, which proved not to be of general application because many furnaces have no suitable location for Pitot tube measurements. In the second technique, therefore, radon was injected into, and traced through, the system. This technique is applicable to all furnaces, and permits a much more detailed survey to be made of the flow in furnace systems, including leakages at valves. Investigations of flow are usually accompanied by temperature measurements of the preheated air supply. The many instruments such as suction pyrometers, radon tracer and various calibration equipments needed for this field of work are kept at the Association's Sheffield laboratories ready for use at member firms' works.

Work carried out in the Sheffield laboratory itself includes a number of intensive studies on the chemical engineering aspects of mixing metals and slags. Experiments have been done on the rate of reaction between metal and slags using various methods of stirring. Some of the more spectacular of these involve breaking down the molten iron into very small droplets (1 mm. diameter and less), and allowing them to fall into the molten slag. In all such experiments the iron-slag mixtures were water-quenched within a minute or so after the additions of iron, and by carefully crushing the slags it was possible to extract the iron droplets, grade them into various size fractions and determine their sulphur contents. The results showed that it was possible to effect a high degree of desulphurization ( 80 per cent or more) in seconds of time provided a sufficient degree of slag/metal mixing could be achieved. However, the experience obtained suggested that atomization methods would be impractical on a large scale.

The Steelmaking Division has at the laboratories a 10-cwt. electric arc furnace of a design to facilitate experimental work. This is being used for, among other things, studies of the economics of this method of steelmaking with the view of possible extension of its field of usefulness. Many types of high-quality bulk steel which it would be technically advantageous to make in electric arc furnaces are only just beyond the economic borderline, and comparatively small improvements in electric furnace practice might bring them over. In particular, power and electrode consumption are being studied both on production furnaces and on the experimental furnace. The experimental furnace has a very large transformer for its size $(500 \mathrm{kV}$. amp.), and the effects of high power inputs are being examined. The biggest effect so far found is, naturally, that of rate of power input during melting down on power consumed during this period, and in the Association's furnace about 20 per cent less power is required with an input-rate of $500 \mathrm{kV}$. amp. than with $250 \mathrm{kV}$. amp.

A further important purpose of the furnace is to provide molten steel for a variety of experiments, mainly on problems of casting. A commercial-scale continuous casting plant to the Association's design is now being built at a Sheffield works, and work continues on the many practical problems involved.

\section{Mechanical Working Division}

The Mechanical Working Division has a wide range of metal-forming and experimental plant housed in a fine, one-story building of $10,000 \mathrm{sq}$. ft. floor area. A 14-ft. four-high reversible cold-rolling mill is equipped to allow as wide a field of cold-rolling research as possible to be undertaken. Operating conditions have therefore been extended far beyond the normal production limits. At present the mill is equipped with a method of automatic gauge control developed by the Association on the basis of some years of work on the causes of gauge variation in rolled strip, in the course of which useful fundamental contributions to knowledge of the plastic behaviour 
of metals have been made. Continuous measurement by roll force meters of the separating force of the rolls indicates gauge variation; this is fed into a control circuit which immediately corrects variation either by altering the strip tension or the gap between the rolls. As an example of the potentialities of the method, a rundown of gauge of nearly $0.002 \mathrm{in.}$ on 0.049 in. between $30 \mathrm{ft} . / \mathrm{min}$. and $250 \mathrm{ft} . / \mathrm{min}$. regularly occurred on an experimental 10-in. twohigh mill without automatic control; with it, the entire strip was held to within \pm 0.0001 in. at all speeds. The demonstration was repeated on a much larger scale by equipping a 56-in. wide four-stand cold reduction mill, one of the largest of such plants in Europe, with a similar type of control. It was found possible, even on this scale, to roll consistently at all speeds to far closer tolerances than are at present possible without automatic control.

After these trials and demonstrations, a period of intensive development is necessary, in which the Association's 14-in. experimental mill will play an important part. The best methods for development have yet to be decided, and there are other rolling variables, such as thermal expansion and bearing clearance, which may need to be considered and which threaten to increase the complexity of the equipment needed.

Other experimental metal-working plant includes a 200-ton capacity hydraulic forging press and $\varepsilon_{0}$ high-speed two-hole wire-drawing machine with a maximum finishing speed of $5,000 \mathrm{ft}$. per min. The press is being used to study the effect of forging strain on mechanical properties. Different tool-ratios and reduction-rates are being used, and attempts are being made to correlate the resulting mechanical properties within the material with the actual forging strains as determined from geometrically similar experiments using 'Plasticine'. It may then be possible to specify with more certainty the optimum forging reduction and the sequence of operations necessary to produce desired properties.

The wire-drawing machine is being used for examining problems of high-speed wire-drawing, in particular the limitations imposed by lubrication. The film thickness of the lubricant is being studied by measuring the electric resistance of the die-wire interface. This resistance is much larger than one would expect if the film were only a few molecules thick. Moreover, it is markedly dependent on speed. In one instance, the resistance increased from about 10 obms per sq. cm. at $5 \mathrm{ft}$. per min. to about $50 \mathrm{ohms}$ per sq. $\mathrm{cm}$. at $50 \mathrm{ft}$. per min. with peaks exceeding 500 ohms per sq. cm. Experiments at speeds prevalent in industry are in progress and give a similar picture. Current investigations are also concerned with improved methods of applying the lubricant; for example, by electrodeposition from solution on to the moving wire. It is hoped to obtain in this manner a more consistent thickness of lubricant film and therefore a more uniform performance of the die.

The success of experimental research in metalworking depends to a large extent on the development of theory both to guide the choice of experiments and also to enable the results to be effectively interpreted. There is within the Mechanical Working Division a section concerned with theoretical plasticity, which has made useful contributions to the practical work. Exact and approximate plastic-rigid solutions have been shown by experiment to be $a$ good guide to the behaviour of real metals.

\section{Metallurgy Division}

The Metallurgy Division at Sheffield includes facilities for heat-treatment, geveral metallurgical examination, mechanical, magnetic and electrical testing and X-ray structural studies as well as for chemical, spectrographic and vacuum fusion analysis. The fatigue-testing laboratory and the high-frequency electric furnace, in which $56 \mathrm{lb}$. of metal may be melted and cast in vacuo, are of particular interest.

An important part of the work is concerned with researches on pure materials. Small variations in the amounts of residual elements found between different casts of a steel having a given nominal composition can have a large effect on its properties. Research concerned with the effects of composition on the properties of steels carried out on alloys made from pure materials provides valuable background information. As such research is expensive and cannot be undertaken by every industrial laboratory, it is particularly suitable for a research association. At present this work includes the study of the effects of nitrogen and carbon on the strain-ageing characteristics of pure iron, and the effect of impurities on the magnetic and electrical properties of pure silicon-iron sheet, while a study of the properties of alloys made from pure materials, and having compositions similar to the nominal compositions of commercial steels, is contemplated.

In the studies of silicon-iron sheet of the type used for transformer cores, the effect of small controlled amounts of nitrogen are being studied with the view of determining the indirect effect which nitrogen has through its influence on the crystallographic texture of the cold-rolled sheet, and the direct effect of nitrogen as an impurity. The variations in texture are being studied with a torque magnetometer which gives an indication of the anisotropy, and also by orthodox $\mathrm{X}$-ray methods which give quantitative information about the texture. The magnetic properties of the silicon-iron are being studied by means of a standard instrument.

The fatigue laboratory is equipped with twelve fatigue-testing machines of the two-point loading rotating bending type, similar in design to those used by the Mechanical Engineering Research Organization and the National Physical Laboratory. The speed of the machines is controlled, and rates up to 5,000 r.p.m. are possible, at which speed the machines are clear of any resonance which might influence the results. Each of the twelve machines is therefore able to provide approximately 7,000,000 stress cycles every $24 \mathrm{hr}$.

The main programme is concerned with the systematic sampling of three commercial casts of steel, using some 3,000 test pieces, to gain information on likely variations within casts of steel and between different casts of steel of the same specification. Information is also sought on whether structural variations in the ingot give rise in the rolled or forged products to significant variations in fatigue properties, and if they do, whether these variations are more pronounced in some ingots of a cast of steel rather than in others. The programme takes into account the fact that it is now widely appreciated that such values as fatigue life, fatigue or endurance limit are not exact values but are, in fact, statistical in nature. It has therefore been planned in collaboration with the Association's operational research section. 